\title{
INFORMATION AND COMMUNICATION TECHNOLOGY (ICT) AND SERVICE DELIVERY IN NIGERIAN PUBLIC SECTOR: A STUDY OF FEDERAL INLAND REVENUE SERVICE (2000-2019)
}

\author{
Edem Edemekong Edemidiong \\ Department of Political Science and Public Administration Faculty of Social Sciences, \\ University of Uyo Akwa Ibom State \\ Ebong, Itoro Bassey \\ Department of Political Science and Public Administration Faculty of Social Sciences, \\ University of Uyo Akwa Ibom State \\ Osezua Ozinegbe \\ Department of Political Science and Public Administration Faculty of Social Sciences, \\ University of Uyo Akwa Ibom State
}

Article DOI: https://doi.org/10.36713/epra5449

\begin{abstract}
This paper examined the impact of Information and Communication Technology (ICT) on the level of services delivered by the Federal Inland Revenue Service (FIRS). The paper was premised on the perceived importance and role of the online platform in the prompt payment of corporate tax as its efficiency in increasing compliance while decreasing the level of tax evasion by corporate bodies. A related challenge that is increasingly being faced by users of electronic facilities for government transaction is a lack of universal security mechanism that forms a first line of defense for such users. The objective of the paper was to examine the impact of ICT on the level of revenue generation efforts of the FIRS and the level of tax evasion in Nigeria. Technology acceptance model was used as theoretical framework of analysis. The paper adopted survey and descriptive research design to elicit responses from the study sample. Both primary and secondary sources of data were used in eliciting information needed for the study. Pearson pear product and chi-square method were used as statistical method of analysis. The major findings of the study revealed among others that application of ICT will only amount to negligible level of revenue generation. It was also revealed that the relationship between application of ICT and the level of tax compliance and acceptability is not significant. Based on the findings, the paper recommended among others, that the government and their agencies should embark on an all-important campaign for attitude and behavioral change with regards to encouraging people in the business world to perceive tax as an obligation to the state and not just a yearly ritual that must be embarked upon by them.
\end{abstract}

KEYWORDS: Federal Inland Revenue, Information Communication Technology, Taxation and Service Delivery 


\section{INTRODUCTION}

The need to reform the bureaucracy for effective service delivery has made governments all over the world to modernize administrative practices and management systems. In this regard, Information Communication and Technology (ICT) is the answer. Information and Communication Technology (ICT) is seen as a tool to support the work of governmental institutions and agencies with the objectives of delivering public services and information in a more convenient, citizen-centric and cost effective manner. Information and communication technology is rapidly changing economic and social activities thereby providing opportunities and challenges for making progress with accelerated growth, poverty reduction and the evolution of the knowledge- based economy in Africa.

The adoption and usage of Information and Communication Technology (ICT) in tackling challenges has been formally researched into and discussed upon at various length, both in Nigeria and the World at large. The increase in Information and communication technology has made public and private sector services become more and more automated and less paper work than in the past as averred in the Central Bank of Nigeria reports and statistical bulletins and other literature (Kozak, 2005).

The extensive use of ICT is changing the way and manner people or companies work. ICT help in areas such as information gathering and dissemination, inventory control and quality service delivery. Service delivery has continued to be a major challenge to public services in Nigeria. This affects all citizens who demand quality services from public services. Like other developing countries, Nigerian government has recognized the importance of ICT for making service delivery prompt and effective and thus has introduced ICT in different public offices. This is because the use of automated systems has been proven to be capable of introducing massive efficiencies to business processes at a minimal cost, due to the bureaucratic structure of government which is costly to manage with little or no result.

Effective service delivery relates to the cost effective, easy and timely access to the services provided by the offices. In this regard, E-revenue administration is one of the systems introduced by the government institution, Federal Inland Revenue Service (FIRS), in 2007 after passing it into law, to provide services to the public by using ICT as a major tool (Abdullah, 2008). However it is observed that despite the advantages that comes with the use of ICT by the FIRS to conduct government business (revenue generation through taxation), deep concerns have been raised about the administrative feasibility of effectively taxing commercial transactions conducted on the Internet by the institution. Indeed, it presents for tax administration the dangers of inefficiency on the one hand, and mistreatment of the tenets of sound tax policy on the other, with concomitant loss of tax revenues from fiscal authorities.

Specifically, the cardinal principles of taxation such as fairness, neutrality and avoidance of double taxation may become compromised or eroded, while opportunities for tax avoidance and evasion tend to rise. It has also been observed that the potential for tax avoidance heightens as physical location becomes unclear, such as what is often obtained in an E-commerce environment. Indeed, there is growing evidence that the internet is being exploited by consumers for tax avoidance. Several researches indicate that firms take advantage of the Internet to minimize VAT payments, and on-line transactions generally assist in the avoidance of consumption taxes, such as Goods and Services Tax.

Poor internet facility, poor electricity to power host server, high cost of maintenance of ICT facilities, lack of technical know-how by tax administering agencies, high level of illiteracy among lower income earners that characterized the population, incidents of internet hackers, infrastructural decay also posed a great challenge to the use of ICT in revenue allocation and mobilization. The infrastructure required for this critical business-to-business interface are often inadequate or lacking in developing countries such as Nigeria. A related challenge that is increasingly being faced by users of electronic facilities for government transactions is a lack of universal security mechanism that forms a first-line of defense for such users. This problem has exposed local firms and individuals to substantial avoidable losses that negatively impact on their income, profitability, and ultimately the tax revenue derivable from them. Further compounding these problems is evidence of a relatively slow acceptability and adaptability of firms and individuals to the reality of conducting transactions electronically, which has manifested itself in the apathy or even resistance to use of e-payment for financial transactions. Indeed, this has been the reason for the recent compulsion of physical cash payment limits instituted by the Central Bank of Nigeria in 2012. These issues, among others, have jointly impacted on the tax revenues realized from e-commerce activities in Nigeria especially on AMS, online purchasing, Point-of Sale and mobile phones. From the foregoing, the purpose of this paper is to investigate the impacts of information communication technology application on the level of service delivery in Federal Inland Revenue Service in Nigeria. 
General Objective

\section{OBJECTIVES OF THE STUDY}

The main objective of this study is to examine the impact of the application of Information and Communication Technology (ICT) on service delivery by Federal Inland Revenue Service (FIRS) in Akwa Ibom State.

\section{Specific Objectives include:}

i. To examine the benefits of ICT application on the level of revenue generation efforts of the FIRS in Nigeria.

ii. To assess the impact of ICT application on the level of tax compliance and acceptability by tax payers in Nigeria. iii. To assess the challenges of adopting ICT in tax administration by FIRS in Nigeria.

iv. To identify measures that should be adopted to enhance better performance of the FIRS through the application of ICT.

\section{Research Hypotheses}

The following hypotheses guided this study:

i. The application of ICT is likely to improve the level of revenue generation of FIRS.

ii. The application of ICT tend to reduce the level of tax compliance and acceptability by tax payers in Nigeria.

iii. Poor internet facility and infrastructure decay poses a great challenge toward adopting ICT in tax administration by FIRS in Nigeria.

\section{Population and Sample of the Study}

Within the context of this study, population relates to the service seekers and service providers which in this case are the employees of the FIRS. The exact number of service seekers cannot be traced so the population size of service seekers is indefinite, while the population size of service providers which was limited to the staff of FIRS in Akwa Ibom state were 110. Out of this number, 60 persons were selected as sample from the service provider to respond to the research questionnaire meant for them. However, the researcher was able to retrieve 45 copies of completed questionnaire from the FIRS employees. Since the service seekers are limited to corporate bodies duly registered with the Corporate Affairs Commission, twelve (12) Public Liability Companies agreed to take part in the study on the conditions that they are treated with strict anonymity. To this end, ten (10) employees were selected from each of these organizations to form part of the sample of this study. It is worthy to note here that the inclusion of the service seekers was to examine their perception on the various online platforms provided by the FIRS to ensure efficiency, accountability and transparency.

The paper adopted multi-stage sampling technique (cluster, stratified and simple random sampling techniques) to select the sample for this study. This was done based on departmental/unit levels for both staff.

\section{Theoretical Framework}

The paper adopted Technology Acceptance Model (TAM), developed by Davis et al.(1989) as a theoretical frame work. Unlike the Theory of Reasoned Action, Technology Acceptance Model excludes the attitude construct in order to better describe intention parsimoniously. It has two constructs, which are perceived ease of use (PEOU) and perceived usefulness (PU), and these constructs determine a user's attitude towards use of that technology, which in turn, influences the behavioral intention to use technology. Perceived usefulness (PU) is defined as the user's perception of the degree to which using the system will improve his or her performance in the workplace, while perceived ease of use (PEOU) refers to the user's perception of the amount of effort needed to use the system (using a particular system would be free of effort).

A key purpose of TAM is to provide a basis for tracing the impact of external variables on internal beliefs, attitudes, and intentions, and it suggests that perceived ease of use (PEOU) and perceived usefulness (PU) are the two most important factors in explaining and predicting system use (Davis,1989). However, some scholars confirm that external variables are mediated by PEOU and PU and that any additional variable contributes little to the explanation of the variance in IT systems. Some scholars also affirm that the external variables provide a better understanding of what influences PU and PEOU, and their presence guides the actions required to influence greater use of IT systems.

\section{The Concept of Federal Inland Revenue (FIR)}

\section{CONCEPTUAL LITERATURE REVIEW}

The Federal Inland Revenue Service is the agency established in 1943 with the responsibility of assessing, collecting and accounting for tax and other revenues accruing to the Federal Government of Nigeria under the 
supervision of a board called Federal Board of Inland Revenue (FBIR). The Institution deals with the taxation of all limited liability companies in Nigeria.

\section{Mandates and operations}

Statutory and administratively, the FIRS has the responsibilities for the assessment, collection and accounting of taxes to the government. Most of their responsibilities includes:

i. The timely provision and publication of accurate data and annual reports to the Federal Government of Nigeria and other stakeholders to inform national economic planning, academic research, tax policy and development legislation.

ii. The timely provision of tax advisory services, rulings, guidance notes and clarifications on request and to the public in general.

iii. The regular investigation, enforcement and prosecution of tax defaulters as provided by the law

iv. The issuance of " Tax Identifying Number" (TIN) at no cost to the tax payers

v. The prompt processing of payment claims and tax refund requests received, within stated timeframes

vi. Undertake appropriate actions to reduce the arrears position of the service and minimize debt profit.

vii. The regular and accurate reconciliation of taxes received into the Federation, Consolidated and VAT as the case may be.

viii. Provision of tax education and information to tax payers through diverse channels and languages.

\section{Management of FIRS}

The Management of the Federal Inland Revenue Service (FIRS) as part of its mission statement to achieve corporate vision and value is out to:

i. $\quad$ Collect taxes according to law through actively encouraging voluntary compliance.

ii. $\quad$ Prosecute the tax law very vigorously thereby deterring tax evasion and avoidance;

iii. Maximize tax collections through effective and extensive coverage of the whole country.

iv. Maintain public confidence in the integrity of the tax system by administering the tax laws and regulations fairly, uniformly and courteously.

v. Recognize the tax officials as important human assets in the achievement of the set objectives.

In order to achieve the above stated mission statement, the organization places high premiums on:

i. Human resource development

ii. Staff motivation

iii. Professionalism

iv. Dedication and loyalty

v. Accountability and transparency,

vi. Information technology and

vii. Effective communication.

However, there are four (4) levels of management within the Federal Inland Revenue Service. This arrangement is put in place to promote regular supervision and monitoring of the entire system thereby facilitating performance evaluations. The four levels of managements include the headquarters, the regional coordinating offices, the large tax offices and the integrated tax offices.

A. The Headquarter

The Headquarters is made up of the Chairman-in-council with the seven directors. The Headquarters is located in Abuja with a liaison office in Lagos. There are seven directors who are in charge of the following departments at the Headquarters.

i. $\quad$ Large tax payer department.

ii. $\quad$ Audit department

iii. $\quad$ Process operations department.

Iv. Tax policy, research and development department

V. Regional Coordination Department

vi. $\quad$ Administration and supplies department

vii. $\quad$ Finance and accounts department

In addition there are some service divisions, branches and units which are headed by Head of Departments who report directly to the Executive Chairman. They are part and parcel of the Headquarters with their functions spanning throughout the entire service. These are:

i. Internal Audit

ii. Legal Service

iii. Corporate Communications,tax payer education and services. 
iv. Investigations and intelligence.

v. Quality assurance and change project coordination

vi Staff discipline

vii Board secretariat

viii Special assistant to the Chairman FIRS.

B. The Regional Coordinating Offices

There are seven regional coordinating offices which replaced the former zonal offices namely, Lagos, Western, North West, South-South, Eastern, North East and North Central Regions. The Regional Co-coordinators and located in Lagos, Ibadan, Kaduna, Port-Harcourt, Enugu, Maiduguri and Jos respectively.

C The Large Tax Offices

There are five (5) large tax offices spread across the country with two offices designated for non-oil and oil and gas located in Lagos while one office each in Kano, Port-Harcourt and Abuja. These offices are headed by Tax Controllers.

\section{Organizational Structure and Board of FIRS}

According to the FIR, the organizational structure of FilIRS consist of

i. $\quad$ Executive chairman

ii. Nine members with relevant qualifications and expertise appointed by the president to represent each of the nine (9) geopolitical zones

iii. A representative of the Attorney General of the Federation

iv. The Governor of the Central Bank of Nigeria or his representative

v. A representative of the minister of Finance not below the rank of director

vi. The chairman of the Revenue Mobilization, Allocation and Fiscal Commission

vii. The Group Managing director of the Nigerian National Petroleum Corporation

viii. The Comptroller General of the Nigerian Custom Service or his representative not below the rank of Deputy Comptroller General

ix. The Registrar-General of the Corporate Affairs Commission or his representative

$\mathrm{x}$. The chief executive officer of the National planning commission or his representative

\section{The Concept of Information and Communication Technology (ICT)}

Information and communication technologies (ICT) refer to technologies that provide access to information through communications. It is similar to information technology (IT). But primarily focuses on communication technologies. This includes the internet, wireless network, cell phones, and other communications medium. ICT can be defined as technologies that enable recording, processing, retrieving and the transmission of information or data.

To Wangwe, (2007), ICT is an integrated system that incorporates the technology and infrastructure required to store, manipulate, deliver and transmit information, the legal and economic institutions required to regulate ICT access and usage, and the social and inter-personal structures which allow information to be shared, facilitate access to the ICT infrastructure, and through which innovation takes place.

Herselman and Hay (2003), described ICT as technologies that support the communication and cooperation of "human beings and their organizations" and the "creation and exchange of knowledge. Furthermore, $\mathrm{Yu}$ (2010) considers ICT as a range of technologies that allow the gathering, exchange, retrieval, processing, analysis and transmission of information. In order words, ICT can be described as any tool that facilitates communication, process and transmit information and share knowledge through electronic means.

Rwashana and Williams (2008) advocate that ICT encompasses a range of electronic digital and analog devices such as radio, television, telephones (fixed and mobile), computers, electronic-based media such as digital text and audio-video recording, and the internet, but excludes the non-electronic technologies. Selwyn (2002) in his opinion refers to ICT as "an umbrella term that includes computer hardware and software; digital broadcast and telecommunications technologies as well as electronic information repositories such as the World Wide Web or those found on CD-ROMs".

Sewanyana (2009) further describes ICT as a strategic tool that allows users to become more efficient and effective. The use of information communication and technology (ICT) to support the work of governmental institutions and agencies with the objectives of delivering public services and information in a more convenient, citizen-centric and cost effective manner is called e-governance. In other words, it is the use of ICT for promoting 
more efficient and cost-effective government, more convenient government services, greater public access to information, and more government accountability to citizens.

An electronic transaction involves the exchange of goods and services between businesses (including affiliates), households, individuals, governments, and other public or private organizations through sale or purchase, conducted over computer-mediated networks for which payment and delivery may be carried out either on or offline. As such, any form of electronic order, whether payment is made through the same network or not, is covered here. The electronic medium may include proprietary networks such as those used for electronic data interchange (EDI), telephony, etc. Furthermore, the basic parties involved in the exchange are consumers, businesses or government, operating in a business-to-business, business-to-consumer or business-to-government combination (UNCTAD, 2001).

The table below shows the important of Electronic devise to governmental sectors

Table 1.1 Benefits of Electronics Service Delivery to the Public and government

\begin{tabular}{|l|l|l|}
\hline S/N & Benefits to Service provider & Benefits to service seekers \\
\hline 1 & $\begin{array}{l}\text { Reduce need for paper forms and } \\
\text { manual data entry }\end{array}$ & $\begin{array}{l}\text { All day access to information and } \\
\text { services }\end{array}$ \\
\hline 2 & $\begin{array}{l}\text { Reduce number of face to face } \\
\text { inquires and eliminates time } \\
\text { consuming manual process }\end{array}$ & $\begin{array}{l}\text { End long line at government } \\
\text { offices }\end{array}$ \\
\hline 3 & $\begin{array}{l}\text { Latest technology used to } \\
\text { streamline operations }\end{array}$ & $\begin{array}{l}\text { Eliminate need to fill out paper } \\
\text { forms }\end{array}$ \\
\hline 4 & $\begin{array}{l}\text { Allows agencies to give higher } \\
\text { level of services in this time of } \\
\text { reduced budgets. }\end{array}$ & $\begin{array}{l}\text { Dealing with government entity } \\
\text { will change from hindrance to } \\
\text { convenience. }\end{array}$ \\
\hline
\end{tabular}

Source: Andrade (2007).

\section{Concept of Taxation}

Ishola (1999) defines taxation as compulsory payments made by the individuals, partnerships and companies to the government coffer as a percentage of their annual income primarily with the aim of raising revenue and secondly with the aim of directing the factors of production towards government objectives for that period. Aji (1997) in his own contributions defines taxation as "compulsory contribution to the support of government, levied on persons, property, income, commodity and transaction mostly proportional to the amount on which the contribution is levied". It is the imposition of levies by government upon persons or property for the purpose of raising fund. The reason for such levy is to support the government in the provision of essential services for the people of the country.

The most significant enactment on companies' tax is the companies' income tax Act (CITA) No. 28 of 1979 which replaced the CITA 1960. CITA 1979 codifies all the companies' income tax enactments since 1961. Between 1979 and 1991, there were amendments to CITA (1979). All the amendments are Finance (Miscellaneous Taxation Provisions) Decrees namely:
i. $\quad$ Decree 98 of 1979
ii. Decree 4 of 1985
iii. $\quad$ Decree 12 of 1987
iv. $\quad$ Decree 31 of 1989
v. $\quad$ Decree 55 of 1989
vi. $\quad$ Decree 21 of 1991
vii. $\quad$ Decree 63 of 1991

The above seven (7) amendments in conjunction with the decree No. 31993 make up the Nigerian tax law 1995 first edition prepared under the authority of Federal Inland Revenue Service which came to force on 31st day of December, 1993. Companies income tax is chargeable on the income of all companies operating in the country except those specifically exempted under the Act.

The use of ICT in taxation enhance performance in revenue administrations by reducing human error and processing times, providing readily accessible data for tax officers, promoting voluntary compliance thereby minimizing tax evasion and facilitating better decision making by tax authorities. Many countries have taken a gradual approach by allowing voluntary e-filing and e-payment for select segments of the taxpayer base, e.g. individuals or companies only, in the initial stages to allow for live testing of the system. After testing is complete filing becomes mandatory for some taxpayers, e.g. companies (Dowe, 2008). 


\section{Objectives of Taxation}

The main objective of imposing tax is to raise money to meet government expenditure which includes cost of general administration, internal and external defence, maintenance of law and order and provision of social services. Apart from the above mentioned main objective, various individuals and institution advance other main reasons for the imposition of taxes by government at different levels.

Abdulrasaq (1993) in his contribution reduced the main and other objectives of taxation to three as follows:

i. Raising of Revenue: The raising of revenue to meet government expenditures is a key function of a good tax administration. He stated that with absence of tax, government would find it difficult to carry out its functions while, the ability of government to meet its obligations to the masses may be seriously impaired. Basic social amenities such as education, health, security, defences, law and order cannot be ordinarily provided by the free market. He observed that a review of the developments in Nigeria would show that the level of taxes raised have helped in no small measure in meeting these expenditures.

ii. Re-distribution of wealth: He stated that the redistribution of wealth as an objective is based on two premises. The first being that taxation should basically rest on the ability to pay, thus requiring that the greatest burden be borne by the rich. The second posits thatthe present arrangement of wealth distribution is a potently unjust; hence taxation should have a built -in redistribution function.

iii. Management of the economy: It would appear that greater emphasis is placed on the use of monetary policies in the management of the economy. He emphasized that fiscal policies have helped greatly too in the management of the economy. Such fiscal policies that have been found to be widely used include the various tax reforms which were supposed to increase the people's purchasing power.

FIRS (2002) advance the following key reasons for the imposition of taxes by government;

i. To cover the cost of general administration, internal and external defence, maintenance of law and order, and the social services provided by the government.

ii. To reduce income and wealth in order to reduce inequality.

iii. To control the consumption of goods and services considered nonessential or harmful.

iv. To check inflation by reducing the volume of purchasing power.

v. To service national debt and to provide retirement benefits etc.

vi. To provide subsidies in favour of preferred sectors of the economy, for example agriculture and selected industries.

vii. To implement government policies. Since the budget becomes an adjunct to monetary policies, taxation has often been increased in order to provide a large budget surplus, or reduced to stimulate demand.

viii. To serve as a powerful fiscal weapon to plan and direct the economy by shaping the economic growth and development of a country. Having examined the positions of the various authors on the objectives of tax imposition, the researcher is inclined to agree with the view of Abdulrasaq (1993). The objectives of tax imposition by thegovernment can be summarized under these headings: Revenue Generation;Wealth Redistribution; and Management of the Economy. These three reasons explain why government imposes tax on its citizens and on organizations in any economy.

\section{Features of a Good Tax System}

A good tax system for any country should have the following features as claimed by FIRS (2002):

i. Economic growth facilitator: The taxes should be an effective instrument of economic growth. The long term objective of a good public finance system is economic growth rather-than short run economic stability. So a good tax system should encourage savings and capital formulation and should be suitable for the mobilization of resources for accelerated economic growth.

ii. Employment Stimulator: A good tax system should aim at creating an enabling environment for raising the level of employment and for raising the standard of living of the people.

iii. Tolerable tax burden: A good tax system should ensures that the tax burden on the masses does not exceed its taxable capacity. Tax burden can be minimized by introducing tax reforms that improve the nature of the tax levied, the time and mode of payment.

iv. Minimum Sacrifice: Taxes are levied on incomes and wealth and their payments involved sacrifice on the part of the tax payers. Therefore, it is advocated that a good tax system should aim at minimizing this sacrifice.

v. Highly canonical: A good tax system should be simple to administer as this will minimize the chances of tax evasion and tax avoidance. A good tax system should also avoid multiplicity of taxes. However, to ensure adequate public revenue, the tax system should be broad-based. Taxes should be convenient to the tax payers in terms of the time and mode of payment. 
vi. Common good and maximum social advantage: A good tax system should adhere to this principle of maximum social advantages. It should also ensure maximum benefits to the country as a whole.

\section{Principles of Taxation}

The eight canons or principles as identified by FIRS (2002) and Ishola (1999) which were described as desirable characteristics of a healthy tax system are as follows:

i. The Canon of Equity: This means that the distribution of tax burden should be equitable. The idea embodies the ability to pay. Only when a tax is based on the tax payer's ability to pay, then it can be considered equitable or just. This equity can be either horizontal or vertical. The horizontal equity means that those with the same income should pay an equal amount of tax, while the vertical equity signifies that those with different incomes should pay different amount of tax. The equity may be ensured by a proportional, just as much as by a progressive system of taxation.

ii. The canon of convenience: under this principle, taxes should be conceived in such a way that the manner and time of payment should be suitable to the tax payers.

iii. The canon of certainty: According to the certainty canon, the scope of the tax should be clear; the tax should not be arbitrary. The potential tax payers ought to be aware of the exact amount of tax they are expected to pay as well as the time and method of payment.

iv. The canon of Economy: This implies that the administrative costs of taxes to be collected should not be higher than the revenue to be realized. This principle of taxation requires that taxes should not be imposed if their costs of collection were excessive. A good tax system can be considered economical if the cost collection is not excessive. On the other hand, if the cost of collection takes a large part of the tax collected, the tax is not economical.

v. The canon of simplicity: According to the canon of simplicity, a good tax system should be coherent, simple and straight forward. The tax should be cleared to the tax payers and must be accepted by the public. It is argued that proper understanding of tax system eliminates the chances of corruption and oppression by tax officials.

vi. The canon of flexibility: The tax system should be flexible especially in a federal and democratic nation where there are always change of government. This means the tax system should be responsible to changing realities rather than being rigid. An adjustable tax system would allow any tax found to be obsolete to be removed and replaced with a meaningful and collectible tax.

vii. The canon of Impartiality: This principle recognizes that a good tax system should not discriminate between tax payers under the same and similar circumstances. An impartial tax system ensures that all persons similarly placed pay the same tax.

viii. The canon of productivity/fiscal adequacy: This canon advocates that the yield from a good tax system should be adequate to cover government expenditures.

\section{Concept of Service Delivery}

This refers to a set of principles, standard, policies and constraints to be used to guide the designs, development, deployment, operation and retirement of services delivered by a service provider with a view to offering a consistent service experience to a specific user community in a specific business context (Dzidonu, 2012). It is an act of providing service to customers.

Service delivery is a component of business that defines the interaction between providers and clients where the provider offers a service, whether that be information or a task, and the client either find value or loses value as a result. It can also be defined as any contact with public administration during which customers- citizens, residents or enterprises seek or provide data, handle their affairs or fulfill their duties. These services should be delivered in an effective, predictable, reliable and customer friendly manner.

Due to rapid expansion of the use of Information and Communication Technologies, electronic service delivery is an effective means to reduce costs, both in time and money, for the customer as well as the government. Dzidonu (2012) itemized the benefit of using information technology to manage the operations and delivery of public sector institutions to include: improvement in administrative efficiency, effectiveness and productivity, improvement in service delivery, reduction in administrative, operational and transactional costs of public and provision of access to information at a reduced cost. In relation to taxation, significance of the use of IT is infinite, some of which are; facilitates a reducing in the overhead cost of managing the agencies of government responsible for tax administration, instant computation of tax liability from the use of online tax calculator, reduced cost of registering tax payers and instant generation of tax identification number, reducing in staff-taxpayers collusion as regards tax 
liability, reduction in fraudulent activities of tax collectors in the aspect of non-remittance of tax received from tax payers and boost the revenue of government in terms of reduction in expenses (administrative, overhead and transactional) and corrupt.

Good service delivery requires that:

i. The government understands the needs to promote citizen-oriented administration

ii. Good administration is a policy objective put into practice coherently, through various regulatory and other mechanisms, to ensure quality public services.

iii. Accessibility to public services is ensured

\section{REVIEW OF GENERAL LITERATURE}

Information technologies are tools, devices, and resources used to communicate, create, manage, and share information. They include hardware (computers, modems, and mobile phones), software (computer programs, mobile phone applications), networks (wireless communications, Internet) and basically concerned with the purpose of collecting, processing, storing and transmitting relevant information to support the management operations in any organizations (Adewoye and Olaoye, 2014).

Application of ICT in any organization enhances the production process as monitoring technologies could be used to reduce the number of supervisors required in the process. ICTs are being used for strategic management, communication and collaboration, customers' access, managerial decision making, data management and knowledge management since it helps to provide an effective means of organizational productivity and service delivery (Olugbenga, 2006).

Buhalis (2003) notes that the application of ICT in businesses causes fundamental changes that can provide powerful strategic and tactical tools for organizations if properly applied and used. This could have great impact in promoting and strengthening organizational competitiveness. Krishnaveni and Meenakumari (2010) assert that ICT has played a major role in reducing operational inefficiency and improving decision-making in many areas of governance. Furthermore, Hengst and Sol (2001) affirm that ICT enables organizations to decrease costs, increase organizational capabilities and also, assist to shape inter-organizational coordination. Therefore, the use of ICT can help to lower coordination cost and increase outsourcing in organizations.

Similarly, Ramsey et al., (2003) in their research maintained that organizations generally stand to gain from ICT in areas such as reduced transaction costs. In otherwords, the use of ICT could assist both individuals and companies to access large markets at low cost. In addition, Irvine and Anderson (2008) comment that the use of ICT does not only offer practical benefits for general management, but also enables companies to overcome the disadvantages of place and space.

Heeks (2001) found that the use of ICT can make a significant contribution to the achievement of good governance. Analyzing case studies from countries such as the Philippines, Honduras, Chile and South Korea, the study outlined three key contributors of e-governance: improving government process (e-administration), connecting citizens (e-citizens and e-services), and building external interactions (e-society). He also identified two major challenges that developing countries face when it comes to the successful implementation of e-government: i) the strategic challenge of e-readiness and ii) the tactical challenge of closing design-reality gap, adopting best practice in e-governance projects in order to avoid failure and to achieve success.

Research based article named Aligning ICT for Service Delivery in Nigerian Local Government by Adeyeye and Aladesanmi (2010) had reviewed the challenges facing ICT application and opportunities accruable from it, especially in the area of service delivery. Findings from data in the sampled local governments revealed an incredibly low level of ICT presence and application. Likewise, lack of web presence and web portals had deprived the local government of efficient delivery of basic services; more so, most council were riddled with bureaucratic lethargy. The paper recommended the development of web based application to harvest data, catalyze data processing, develop capacity building, establish telecentres and integrate the local government councils into the national ICT strategic plan.

A research conducted by the Commonwealth Telecommunications Organization (CTO) undertaken in Ghana, India and South Africa has gathered evidence about the demand and supply factors affecting the provision of public services through local e-content. The research report says that, expense was the main reason for respondents not using services in South Africa, while a perceived lack of demand for services was the least important. In contrast, no need for the services was cited as the main reason amongst Ghanaian and Indian respondents, with local language issues cited as the least important (CTO 2007). 
In the research entitled E-Governance and Online Public Service: The Case of a Cyber Island, Taruna Shalini Ramessur of University of Technology of Mauritius has attempted to understand the effect of e-governance via the introduction of a specific eservice (application for learner's license) on service delivery in the Mauritian Public Sector. The research findings indicated that e-governance has improved service delivery of that specific eservice in terms of clearer information, better quality, modernized and personalized service and speedy process. The study claims that that eservices still has certain weaknesses in terms of double processes (physical and online), wrong communication and lack of options for feedback. However, the study has been limited to investigating the Mauritian government in the fast movement of e-government and hence no real generalizable conclusions can be drawn from that specific setting (Ramessur 2009).

Schuppan (2008) in his article E-government in developing countries: Experiences from sub-Saharan Africa addresses the different institutional and cultural contexts which must be considered when implementing Egovernment in sub-Saharan Africa. With the case study of e-governance in Ghana, Tanzania and Kenya, the writer viewed that the development potential of e-government can only be realized if certain minimum preconditions exist in the country or if they are taken into consideration during implementation. Due to institutional conditions in Africa, longer preparations and project times (compared to developed countries) are to be expected when implementing e-government. The article suggested that different administrative contexts and rationalities must be taken into an account when implementing e-government projects and strategies. Thus, the writer concluded that especially for African countries, a context-oriented approach is likely to be a more promising route to the successful implementation of e-government.

Pathak (2008) in his research based article entitled E-Governance Corruption and Public Service Delivery: A Comparative Study of Fiji and Ethiopia has concluded that e-governance is positively related to improved government-citizen relationships and corruption reduction. The study, using a structured questionnaire, explored the perceived role of e-governance in reducing corruption amongst 400 respondents each from Fiji and Ethiopia. The study has suggested that while e-governance initiatives can make important contributions to improving public services they can best do so by helping improve overall relationships between governments and citizens.

Monga (2008) has analyzed the experiences of e-governance at the local, state and federal levels of government in India. The study found that e-governance has brought about a revolution in the quality of service delivery to the citizens by improving transparency in the administrative process, saving time due to single window service provisions, simplifying procedures, reducing corruption, improving office and record management and improving attitude and behavior of civil servants.

United Nation (2008), in its publication UN E-government Survey 2008: From e-Government to Connected Governance has identified the key variables involved in the delivery of back office integration which are the people, process and technology required. Whilst the technology is increasingly resilient and 'fit for purposes', evidence indicates that success or failure is less a technological issue and more a people issue; in particular the ability to change public service cultures and motivate public sector workers to new ways of working, address service cultures, address trade union concerns and provide adequately skilled and competent management and leadership. The study further says that Swedish government has faced critics both internally and externally pointing out that traditional culture of decentralized agency autonomy does not lend itself easily to achieving government-wide capacities. Indeed, the Swedish government, having studied several other European country experiences, concluded that many models being developed elsewhere would not be workable in their context.

Bolgherini (2006) in her article "the technology trap and the role of political and cultural variables: A critical analysis of the e-government policies" had claimed that technology alone does not necessarily provide more access and more participation. As massive technological intervention is not enough for reinventing government online, other variables should be taken into consideration. Factors concerning political culture, cognitive frames and mentality, administrative traditions, as well as the country-specific peculiarities play a relevant role in determining if and how e-government initiatives can succeed or fail. She, thus, argued that any opportunity and push for change and actual influence on administrations, governments, and societies, prompted by the new technologies, should endure important variables of political, social and cultural nature.

Pariyar (2007) in his study E-Government Initiatives in Nepal: Challenges and Opportunities pointed out a number of challenges regarding the e-government challenges by the government. Some of the challenges are: low level of political commitment, poor culture of technology and modest human resources training capacity of local institutions. Bhattarai (2004) studied on prospects and challenges of implementation of e-governance in Nepal. One of the objectives of the study was to highlight issues involved in successful implementation of e-governance related initiatives in Nepal. The study asserted that the effective and meaningful application of ICT call for a synergetic mix of strategies backed by appropriate institutional mechanism, conducive policy and regulatory environment, 
pervasive and dependable ICT infrastructure and focused initiatives aimed at influencing organizational as well as individual behavioral responses. The study further claimed that e-governance as a governance paradigm demands cultural and attitudinal changes on the part of government machinery and public administration apparatus as it seeks to promote transparency, accountability and wider public participation in governance. The study concluded that the success of e-governance depends on attitudes, knowledge and skills especially within the public sector that are required to initiate, implement and sustain e-governance initiatives.

\section{CHALLENGES OF ADOPTING INFORMATION TECHNOLOGY IN TAX ADMINISTRATION IN NIGERIA}

Ideally, the adoption of IT-facilities in administering taxation can leads to a nonchalant attitude on the payment of taxes, garbage-in-garbage-out, that is imputation of wrong figures that will lead to wrong calculation of tax liability by online tax calculator, poor internet facility, poor electricity to power host server, high cost of maintenance of ICT facilities, lack of technical know-how by tax administering agencies, high level of illiteracy among lower income earners that characterized the population, incidence of internet hackers.

The main challenge that ICT poses for the Nigerian tax system, like in most other countries, stems from the fact that the exact national laws governing income taxation are premised on the assumptions of physical presence of parties to business transactions. However, these laws are incompatible with the taxing of internet transactions. Physical presence justifies the concept of permanent establishment, as defined in the double tax treaties. With ICT, the need for physical presence in the country receiving the goods or services is removed, or is at best diminished. This creates a problem of how to determine the right to tax profits that are derived from electronic transactions with serious intrinsic implications for the full realization of income tax revenues. Although the recognition of the Internet as a major platform for communication has grown in recent times, the current poor state of infrastructures required for transactions presents yet another drawback to the widespread use of the Internet for conducting government business in Nigeria. It is important to note that e-commerce does not merely involve a consumer surfing the internet for his needs with his personal computer, but includes interfaces between businesses in order to be able to serve the customer effectively implying that all the players lining up the supply chain must be fully equipped with the Internet and other facilities.

Oseni (2015) opined that the use of ICT can be catastrophic if carelessly employed by both the tax payers and the tax administrators as scammers and hackers of the internet facilities can utilize the ignorance or the lax security of the system.

\section{Hypothesis 1.}

\section{TESTING OF HYPOTHESIS}

Pearson Product Moment Correlation (PPMC) analysis on application of ICT and Revenue Generation. The application of ICT is likely to improve the level of revenue generation of FIRS in Akwa Ibom State

\section{Correlations}

\begin{tabular}{|c|c|c|}
\hline & APPLICATION OF ICT & Revenue Generation \\
\hline $\begin{array}{c}\text { Pearson Correlation } \\
\text { Application of ICT Sig. (2-tailed) } \\
\text { N }\end{array}$ & $\begin{array}{l}1 \\
45\end{array}$ & $\begin{array}{c}0.169 \\
0.038 \\
45\end{array}$ \\
\hline $\begin{array}{ll}\text { Revenue } & \text { Pearson Correlation } \\
\text { Generation } & \text { Sig. }(2 \text { tailed })\end{array}$ & $\begin{array}{l}.165 \\
.038 \\
45\end{array}$ & $\begin{array}{l}1 \\
45\end{array}$ \\
\hline
\end{tabular}

Significant at 0.05 significant level

Source: Statistical Package for social Science (SPSS- Ver.20.0)

Decision: The Pearson Product Moment Correlation (PPMC) analysis on application of ICT and the level of revenue generation has revealed a positive correlation of 0.169 . The implication of the correlation value based on the decision rule is that the relationship between the two variables is not negligible. This further means that the application of ICT will only amount to negligible level of revenue generation. In addition to above, the $\mathrm{P}$ value ( $\mathrm{p}=$ 0.038 ) that is lower than the calculated value of 0.169 at 0.05 level of significant was obtained which implies that the relationship between application of ICT and level of revenue is significant. In this case, it can be affirmed that 
there is a significant relationship between application of ICT and the level of revenue generation by FIRS. Hence, the Null hypothesis was rejected.

\section{Hypothesis 2}

The application of ICT tend to reduce the level of tax compliance and acceptability by tax payers in Nigeria.

Pearson Product Moment Correlation (PPMC) analysis on application of ICT and the level of tax compliance and acceptability by tax payers in Nigeria.

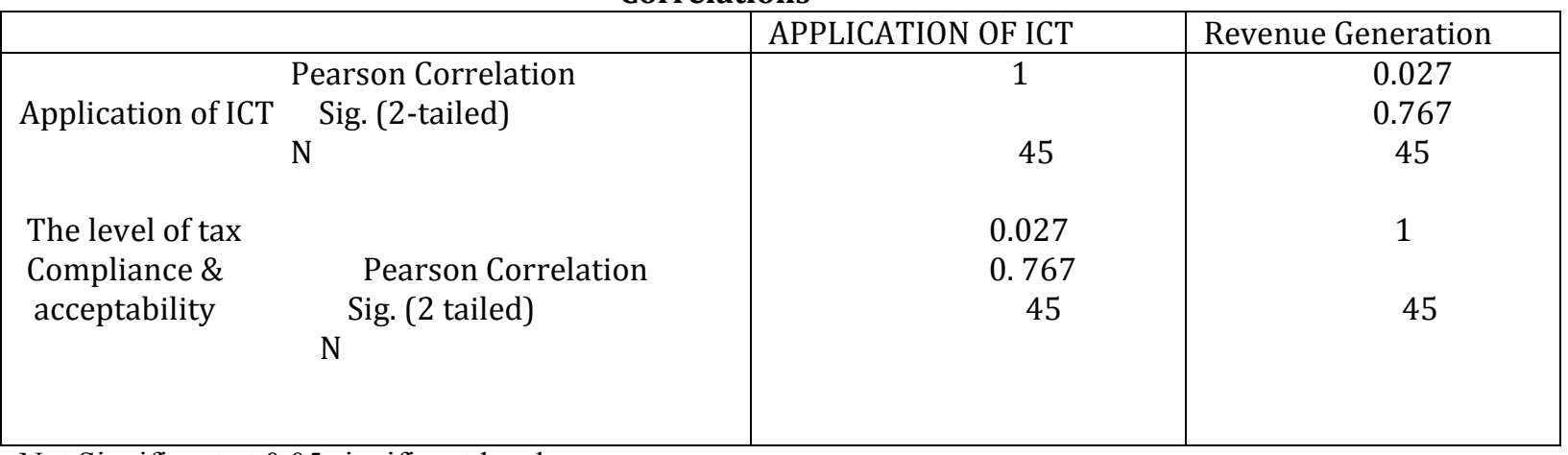

Not Significant at 0.05 significant level

Source: Statistical Package for social Science (SPSS- Ver.20.0)

Decision: The Pearson Product Moment Correlation (PPMC) analysis on application of ICT and the level of tax compliance and acceptability has revealed a low correlation coefficient of 0.027 . Hence, since the table value of 0.767 is greater than the calculated value of 0.027 at 0.05 level of significant, we accept Null hypothesis (HO), and reject Alternative hypothesis (HI). This implies that application of ICT and level of tax compliance and acceptability is not significant

\section{Hypothesis 3}

Poor internet facilities and Infrastructure Decay is like pose a great challenge toward adopting ICT in Tax Administration by FIRS in Nigeria.

Pearson Product Moment Correlation (PPMC) analysis on the challenges of poor internet facilities and infrastructural decay in tax administration by FIRS in Nigeria.

\section{Correlations}

\begin{tabular}{|l|c|c|}
\hline \multicolumn{1}{|c|}{ Pearson Correlation } & APPLICATION OF ICT & Revenue Generation \\
\hline \multicolumn{1}{|c|}{ Application of ICT Sig. (2-tailed) } & 1 & 0.136 \\
& & 0.126 \\
The level of infrastructure & 45 & 45 \\
decay and poor internet & & 1 \\
facility $\quad$ Pearson Correlation & -0.0136 & 45 \\
$\quad$ Sig. (2 tailed) & 0.126 & \\
$\mathrm{~N}$ & & \\
\hline
\end{tabular}

Not Significant at 0.05 significant level

Source: Statistical Package for social Science (SPSS- Ver.20.0)

Decision: The Pearson Product Moment Correlation (PPMC) analysis on Poor internet facility and Infrastructure decay has revealed a positive correlation coefficient of 0.136 . Hence, since the table value of 0.126 is lower than the calculated value of 0.136 at 0.05 level of significant, we accept Alternative hypothesis (HI), and reject Null hypothesis (HO). This implies that Poor internet facility and Infrastructure decay significantly pose a great challenge toward adopting ICT in Tax Administration by FIRS in Nigeria. 
EPRA International Journal of Environmental Economics, Commerce and Educational Management Journal DOI: 10.36713/epra0414 |ISI I.F Value: 0.815|SJIF Impact Factor (2020): 7.572 ISSN: $2348-\mathbf{8 1 4 X}$

Volume: 7 | Issue: $4 \mid$ November 2020

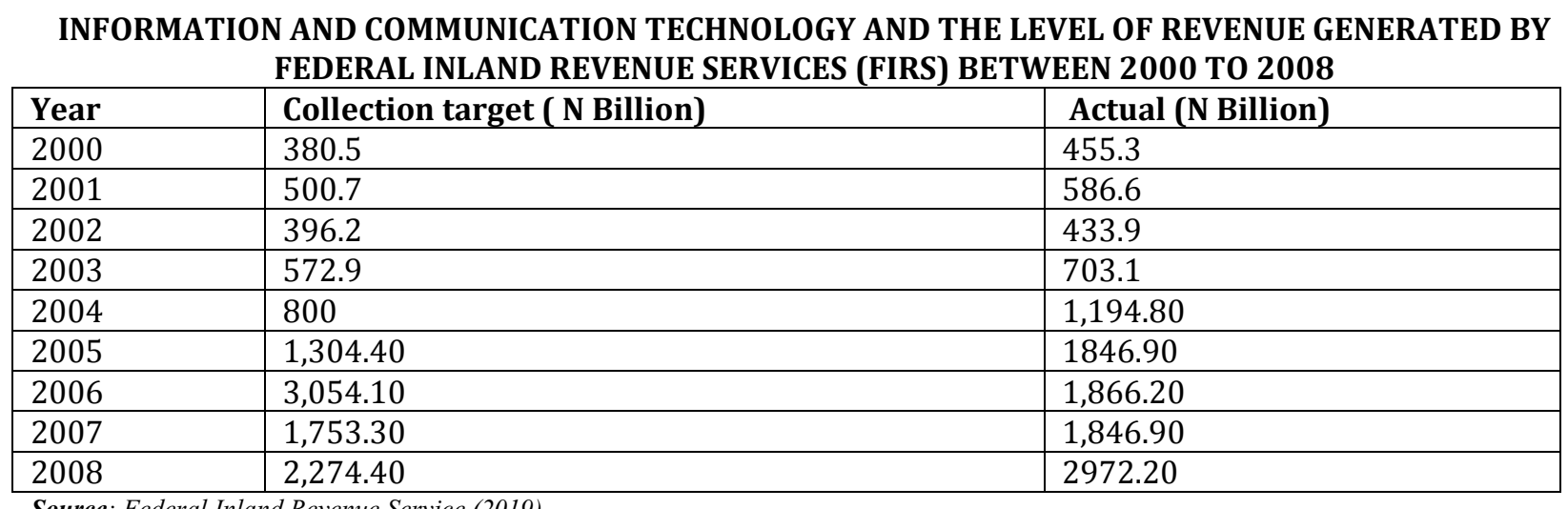

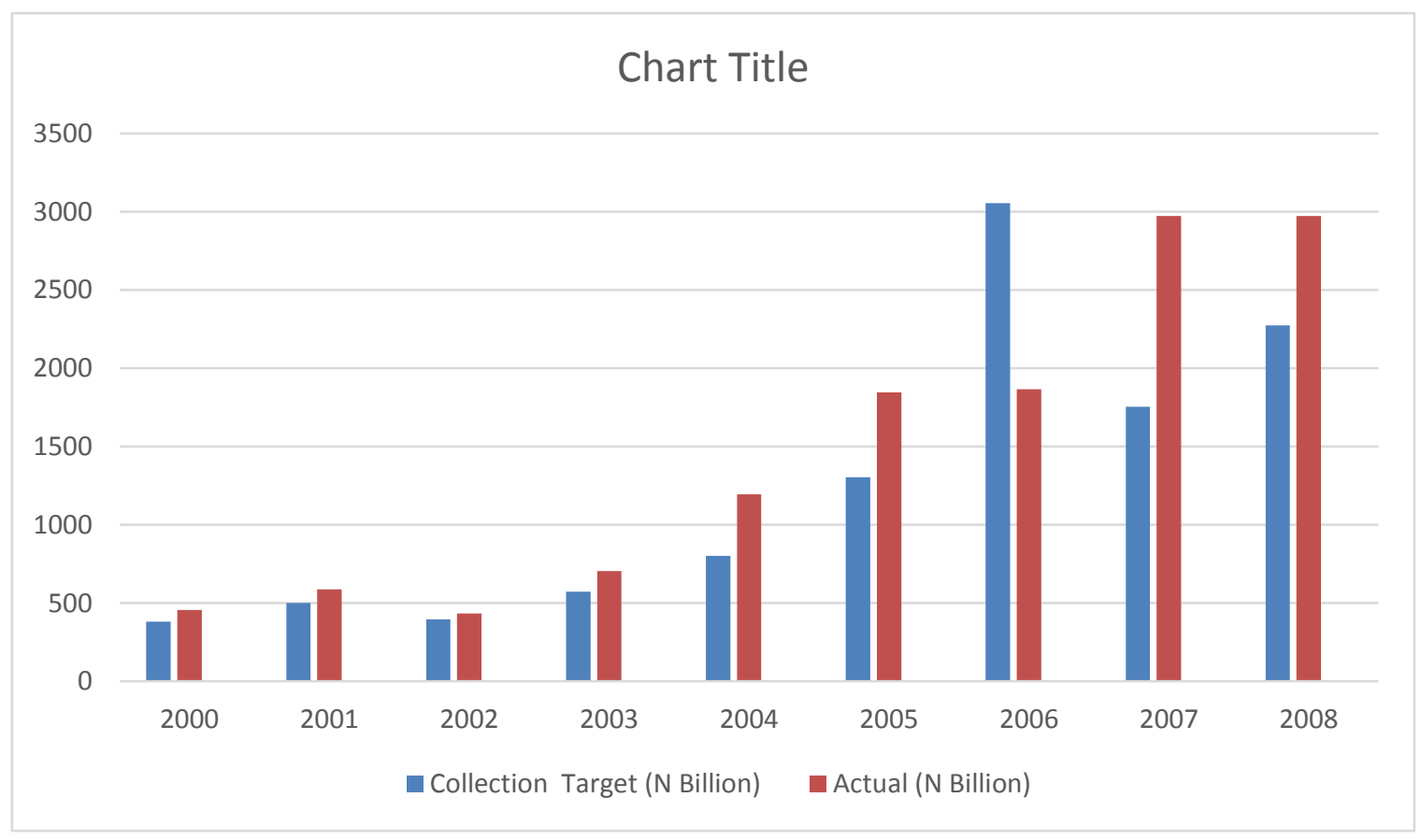

Source: Author Computation (2020)

INFORMATION AND COMMUNICATION TECHNOLOGY AND THE LEVEL OF REVENUE GENERATED BY FEDERAL INLAND REVENUE SERVICE (FIRS) BETWEEN 2009 TO 2018.

\begin{tabular}{|c|c|c|}
\hline Year & Collections Target (N Billion) & Actual (N Billion) \\
\hline 2009 & $1,909.00$ & $2,197.60$ \\
\hline 2010 & $2,557.30$ & $2,839.30$ \\
\hline 2011 & $3,639.10$ & $4,628.50$ \\
\hline 2012 & $3,635.50$ & $5,007.70$ \\
\hline 2013 & $4,468.90$ & $4,805.6$ \\
\hline 2014 & $4,086.10$ & $4,714.6$ \\
\hline 2015 & $4,572.20$ & $3,741.8$ \\
\hline 2016 & $4,200.20$ & $3,307.5$ \\
\hline 2017 & $4,88.9 .70$ & $4,027.94$ \\
\hline 2018 & $6,747.00$ & $5,320.52$ \\
\hline
\end{tabular}

Source: Federal Inland Revenue Service (2019) 


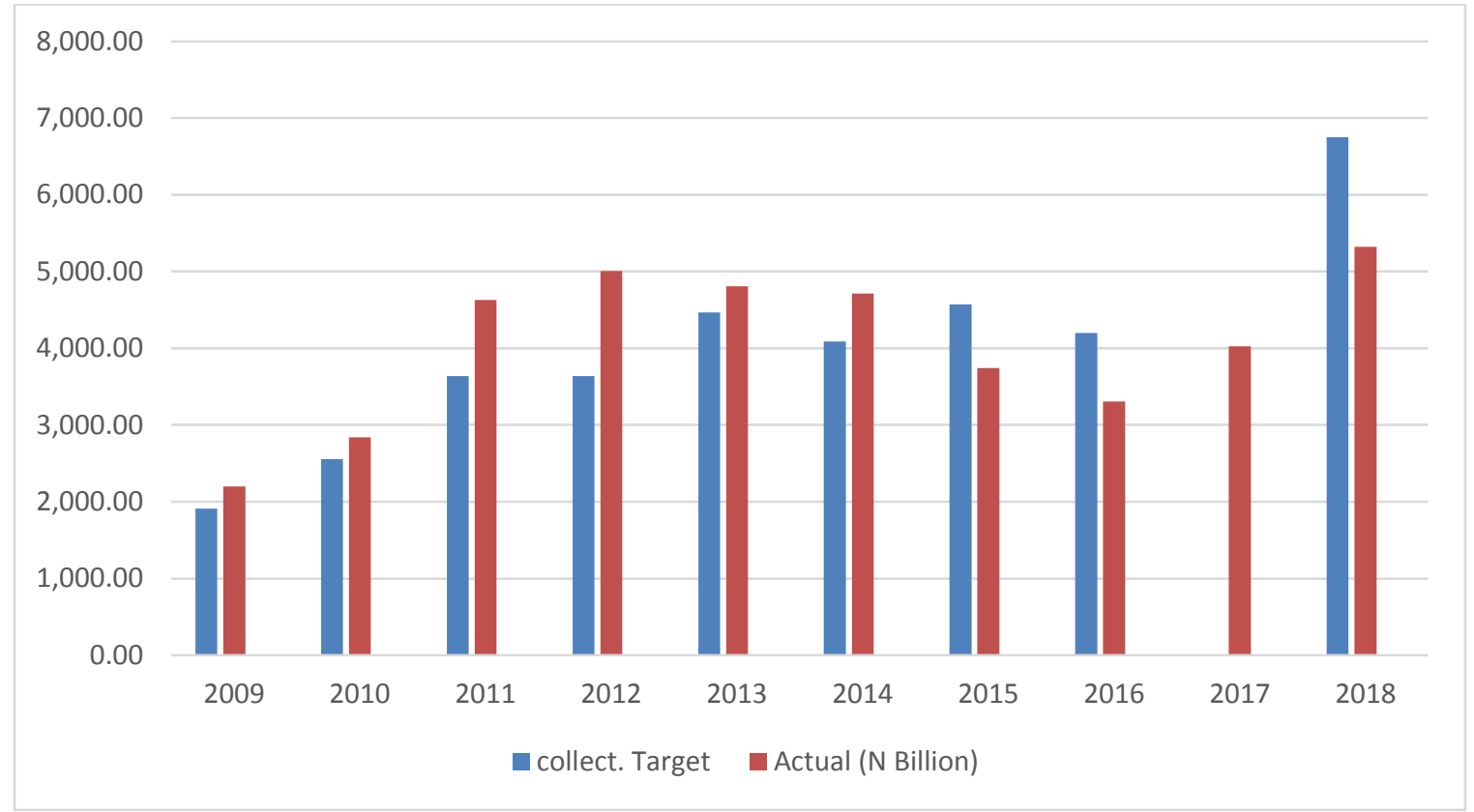

Source: Author Computation (2020).

\section{FINDINGS AND CONCLUSION}

After a careful examination of the relationship between the application of ICT and the level of revenue generation; the level of tax compliance and acceptability; and the level of poor internet facilities and infrastructure decay, it was concluded that not all the dependent variable related positively with the independent variable. Accordingly, the independent variable did not have a significant relationship with all the dependent variable. For instance, it was observed that ICT application had positive and significant relationship with revenue generation. However, on a close observation the researcher noted that this slight increase in the level of revenue so generated from 2007 to 2018 not meeting up with the targets due to economic recession could not be explained for by the poor level of tax compliance by corporate bodies.

This was affirmed by the conclusion that there was no significant relationship between ICT application and tax compliance and acceptability by corporate bodies. The implication of this conclusion is that the increase in tax returns could be context specific and therefore not all tax regions are functional in their tax drive. The researcher alludes to this by concluding that there exist weak links among the tax regional offices. Finally, it was also observed that poor internet facilities and infrastructure decay had a negative relationship on the application of ICT in tax administration by FIRS in Nigeria.

This led to the conclusion that payment of tax by corporate bodies are not perceived as obligatory and therefore not a duty owed the state despite the drive and improvement in both technology and administration that have been alluded to by service seekers is being less time consuming when compared to the former manual system of tax administration.

\section{Recommendations}

Based on the findings of this study, the following recommendations are hereby advanced:

i. First, the government and their agencies should embark on an all impact campaign for attitude and behavioral change with regards to encouraging people in the business world to perceive tax as an obligation to the state and not just a yearly ritual that must be embarked upon by them.

ii. The government should come up with more viable economic policies that will increase the ease of doing business in Nigeria so that existing businesses will be able to make enough profit that will enable them pay tax more easily.

iii. Government should also be practical in showing people and making them understand what they have done so far with tax payer's money and what they will do if more tax are being remitted. 
iv. The government should establish a special court to try corporate tax offenders as well as FIRS officers who aid them to evade tax instead of waiting for the conventional court that delays trial, so that it will serve as deterrent for other offenders.

v. The FIRS should ensure that they work tirelessly to maintain an accurate and up-to-date census of registered companies under its jurisdiction for efficient and effective monitoring, assessment and collection of companies' income tax.

vi. The FIRS campaign should include visiting to corporate offices from time to time to take them on "how and do it yourself" training on the usage of online payment platform. 